\title{
The single nucleotide polymorphism g.133A>C in the stearoyl CoA desaturase gene (SCD) promoter affects gene expression and quali-quantitative properties of river buffalo milk
}

\author{
M. Gu, ${ }^{1,2}$ G. Cosenza, ${ }^{3 *}$ M. lannaccone, ${ }^{3}$ N. P. P. Macciotta, ${ }^{4}$ Y. Guo, ${ }^{2}$ L. Di Stasio, ${ }^{1}$ and A. Pauciullo ${ }^{1}$ \\ ${ }^{1}$ Department of Agricultural, Forest and Food Science, University of Torino, 10095 Grugliasco (TO), Italy \\ ${ }^{2}$ College of Animal Science and Technology, Beijing University of Agriculture, 102206 Beijing, China \\ ${ }^{3}$ Department of Agriculture, University of Napoli Federico II, 80055 Portici (NA), Italy \\ ${ }^{4}$ Department of Agricultural Sciences, University of Sassari, 07100 Sassari, Italy
}

\section{ABSTRACT}

The stearoyl-CoA desaturase $(S C D)$ gene has been investigated in depth in ruminants because of its effect on milk fat composition. In river buffalo, the single nucleotide polymorphism (SNP) g.133A $>$ C in the gene promoter has been associated with milk quality and yield. However, the biological reason for such effects remains unexplored. In this study, we combined mRNA profile analysis, an electromobility shift assay, and quantitative PCR to elucidate the role of this SNP on gene transcription and its effects on milk fat traits. A preliminary genotyping of g.133A $>\mathrm{C}$ was carried out on a group of 303 river buffaloes to choose individuals for the downstream applications. Analysis of allele frequencies showed an increase in the minor allele $C$ (0.25) compared with previous findings (0.16). Six animals (2 for each genotype) were chosen for cloning and 216 positive cDNA recombinant clones for $S C D$ (72 per genotype) were analyzed by PCR. All clones showed the same length on agarose gel; therefore, random clones were chosen for sequencing. No qualitative differences were found and all gene transcripts assembled correctly. An electrophoretic mobility shift assay was performed to evaluate the binding of the transcription factor $\mathrm{Sp} 1$ to DNA sequences including g.133A $>$ C. Genotype $C C$ showed a higher binding (mean \pm standard error of the mean) than genotype $A A$ in 2 different conditions [Enzo buffer (EB), Enzo Life Science Inc., Farmingdale, NY: $201.77 \pm 4.06$ vs. $141.65 \pm 3.77$ band intensity values and Poletto buffer (PB): $95.90 \pm 1.15$ vs. 67.30 \pm 2.14 band intensity values]. The subsequent quantitative PCR confirmed the upregulation of the $C C$ genotype compared with the $A A$ and $A C$ genotypes. The association study with milk fat traits revealed a

Received May 14, 2018.

Accepted September 15, 2018.

*Corresponding author: giacosen@unina.it favorable effect of allele $C$. The heterozygous genotype had the highest values for monounsaturated fatty acids, oleic acid (C18:1 cis-9), polyunsaturated fatty acids, and odd- and branched-chain fatty acids, and the lowest values for saturated fatty acids and atherogenic and thrombogenic indices; the heterozygous genotype differed significantly from the $A A$ genotype. The $A C$ genotype has previously been associated with higher milk yield. Therefore, the g.133A $>$ C SNP is a marker with dual effects and is an interesting candidate for assisted selection programs in river buffalo. These data clarified the biological role of the SNP g.133A $>$ C in the $S C D$ promoter and how it affects gene function, providing important knowledge on the genetic background of lipid metabolism, including the future possibility of selecting alleles with quantitatively or qualitatively favorable effects.

Key words: river buffalo, stearoyl-CoA, transcript, gene expression, Sp1 transcription factor

\section{INTRODUCTION}

In the last decades, the riverine buffalo population (Bubalus bubalis; Mediterranean river buffalo breed) in Italy has greatly increased, reaching more than 385,000 head in 2016 (FAO, 2016), with over 59,000 buffaloes in 272 farms (ANASB, 2017) being officially recorded for production. This positive trend has facilitated the development of a buffalo dairy industry, which currently involves 102 cheese factories officially registered for Buffalo Mozzarella Protected Denomination of Origin (PDO; EC Reg. nos. 1107/1996 and 510/2006), a producers association (https://www.mozzarelladop.it/ consortium/dop-in-numbers), and more than 20,000 operators, with a consolidated turnover of about $€ 720$ million (ISMEA, 2016).

Considering the high market demand for buffalo dairy products, the main breeding goal of the Italian National Association of Buffalo Breeders (ANASB, 
Caserta, Italy) is improvement of milk yield. However, the quality of milk and dairy products is a fundamental prerequisite to satisfy the requirements of national and international consumers. In this context, fatty acid (FA) composition has become a crucial aspect for the assessment of milk's nutritional value. Animal feeding is considered the main source of variation of milk FA composition. However, several studies have demonstrated that genetic variants found in key genes involved in FAs metabolism may be responsible for changes in milk FAs profile (Bionaz and Loor, 2008; Thering et al., 2009).

In this respect, one of the most investigated genes in ruminants belongs to the stearoyl-CoA desaturase $(\boldsymbol{S C D})$ gene family, which comprises 2 isoforms, $S C D 1$ and $S C D 5$, in cattle (Lengi and Corl, 2007). The SCD1 gene, mapped on bovine chromosome 26, codes for stearoyl-CoA desaturase, an endoplasmic reticulum enzyme that plays an essential role in cellular biosynthesis of MUFA. The SCD enzyme catalyzes the insertion of a double bond between carbons 9 and 10 of the FA, activity that is also carried out in the mammary gland (Bionaz and Loor, 2008). In addition, SCD is involved in the endogenous production of the cis-9, trans-11 isomers of CLA, which are generally found in ruminant milk and considered healthy in the human diet (Bhattacharya et al., 2006).

The $S C D 1$ gene has been intensively studied in cattle, where 8 SNP forming 2 haplotypes (A and B) have been found (Medrano et al., 1999). Furthermore, associations between a missense polymorphism in exon 5 (GenBank AY241932: g.10329 $\left.\mathrm{C}^{\mathrm{Ala}}>\mathrm{T}^{\mathrm{Val}}\right)$ and the concentration of some individual FA and FA unsaturation indices in the milk fat have been reported in several cattle breeds (Mele et al., 2007; Moioli et al., 2007; Schennink et al., 2008).

In a previous study, we reported substantial genetic diversity within the river buffalo $S C D$ gene. In particular, 15 SNP distributed from the gene promoter to the $3^{\prime}$ untranslated region (UTR) have been found (Pauciullo et al., 2010). Among them, the transversion FM876222:g.133 A $>$ C in the promoter is considered of particular interest because it falls between 2 binding sites for the transcription factor Sp1. Bioinformatics analysis showed that the allelic form $C$ creates a novel consensus sequence for transcription factor Sp1, and at the same time, generates a putative clustering of 3 consecutive Sp1 binding sites (Pauciullo et al., 2010).

A preliminary analysis of the association between total desaturation index and milk fat (on 22 samples) showed the highest value for homozygous $C C$ buffaloes (Pauciullo et al., 2010). The same marker has been associated with daily milk yield, with genotype $A C$ showing an over-dominance effect (approximately $1.2 \mathrm{~kg} / \mathrm{d}$ ) constant across lactation stages (Pauciullo et al., 2012).
The variability found in the buffalo $S C D$ Sp1 cluster is thought to be responsible for the qualitative and quantitative variation of the gene transcripts and, consequently, of $S C D$ activity. However, despite the substantial impact of this SNP on both milk quality and yield, the biological reason for such effects has so far remained unexplored.

Therefore, in present study, we combined $S C D$ transcript analysis, electromobility shift assay (EMSA), and quantitative (q)PCR to assess the role of the SNP g.133A $>$ C on Sp1 clustering and gene expression. In addition, we investigated possible associations of the genotypes AA, CC, and $\mathrm{AC}$ at the locus g.133A $>\mathrm{C}$ with milk fat traits for their potential application to the quali-quantitative improvement of the productive efficiency of the breed.

\section{MATERIALS AND METHODS}

\section{Sample Collection and Nucleic Acid Isolation}

Fresh milk and blood samples were collected from 303 unrelated lactating Mediterranean river buffaloes reared in 14 farms in southern Italy. Samples were collected in collaboration with ANASB. Milk samples were used for FA analysis as described in Cosenza et al. (2017), whereas blood samples were treated for genomic DNA isolation according to Sambrook and Russell (2001). All DNA samples were diluted with $100 \mu \mathrm{L}$ of Tris-EDTA (TE; $10 \mathrm{~m} M$ Tris, $1 \mathrm{~m} M$ EDTA) buffer, $\mathrm{pH} 7.6$.

Additional individual milk samples were collected from 6 river buffaloes after g.133A $>$ C genotyping (2 for each genotype). The animals belonged to the same farm located in Salerno (Italy), were comparable in age, feeding system, number of lactations (third), and lactation stage (fourth month) and were free of clinical mastitis. These samples were used to perform the quali-quantitative transcript analysis. For this purpose, total RNA was isolated from milk somatic cells using Trizol (Thermo Fisher Scientific Inc., Waltham, MA) according to the manufacturer's instructions. Traces of contaminating DNA were removed using DNase I treatment (Thermo Fisher Scientific). Concentrations of DNA and RNA were measured with the Nanodrop ND1000 spectrophotometer (Thermo Fisher Scientific).

\section{PCR Conditions and Genotyping by Taql PCR-RFLP}

The entire panel of 303 animals was genotyped for the SNP g.133A $>$ C according to the protocol of Pauciullo et al. (2012) with slight modifications in annealing temperature $\left(65.4^{\circ} \mathrm{C}\right)$ and extension time $(20 \mathrm{~s})$. The new primers reported in Table 1 were used to shorten 
the amplified fragment to $201 \mathrm{bp}$. Product specificity was confirmed by ethidium bromide-stained $2 \%$ agarose gel electrophoresis.

Digestion of $5 \mu \mathrm{L}$ of each amplicon was accomplished with $1 \mu \mathrm{L}$ of FastDigest TaqI endonuclease (T $\downarrow$ CGA) in $1 \times$ buffer for $10 \mathrm{~min}$ at $65^{\circ} \mathrm{C}$ (Thermo Fisher Scientific). The digestion products were analyzed by electrophoresis in $2 \%$ agarose gel in $0.5 \times$ Tris-borate-EDTA (TBE) buffer and stained with ethidium bromide.

\section{Reverse Transcription-PCR, Cloning, and Sequencing}

The reverse transcription (RT) of total RNA for the 6 Mediterranean river buffaloes with different genotype for the SNP g.133A $>$ C was conducted using an oligo $\mathrm{dT}_{18}$. The mix was set up in a final volume of $20 \mu \mathrm{L}$ using ImProm-II Reverse Transcriptase (Promega, Madison, WI) according to the standard protocol recommended by the manufacturer. The PCR reaction was performed using the primers in Table 1.

The PCR reaction mix $(50 \mu \mathrm{L})$ comprised $50 \mathrm{ng}$ of

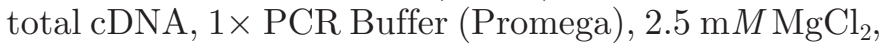
5 pmol of each primer, deoxynucleotide triphosphates at $200 \mu M$ each, and $1 \mathrm{U}$ of Taq DNA Polymerase (Promega). The PCR was performed under the following thermal conditions: $95^{\circ} \mathrm{C}$ for $4 \mathrm{~min}, 35$ cycles at $95^{\circ} \mathrm{C}$ for $45 \mathrm{~s}, 62^{\circ} \mathrm{C}$ for $45 \mathrm{~s}, 72^{\circ} \mathrm{C}$ for $90 \mathrm{~s}$, and a final extension at $72^{\circ} \mathrm{C}$ for $5 \mathrm{~min}$.

The amplified products were first analyzed by electrophoresis on $2 \%$ agarose gel in $0.5 \times$ TBE buffer and then cloned into pGEM-T Easy Vector (Promega). The ligation products were transformed into JM109 HighEfficiency Competent Cells (Promega) following the manufacturer's guidelines. White recombinant clones were randomly chosen and screened by PCR according to Pauciullo and Erhardt (2015) using the following combination of primers: M13 For 5'-GTAAAACGACGGCCAGT-3' and M13 Rev 5'-AACAGCTATGACCATG-3'.

Ten amplicons were chosen from each genotype, purified using NucleoSpin Gel and PCR Clean-up kit (Macherey-Nagel, Düren, Germany) and sequenced in both directions (Microsynth AG, Balgach, Switzerland) using Sanger DNA sequencing technologies.

\section{Agarose EMSA}

According to the genotype, 45-mer single-stranded DNA sequences (Table 1) corresponding to the nucleotides -488 to -444 of the $S C D$ promoter were co-denatured at $95^{\circ} \mathrm{C}$ for $5 \mathrm{~min}$ in $0.2 \times$ saline sodium citrate (SSC) buffer and annealed at room temperature for 2 $\mathrm{h}$ with their complementary sequence to obtain double- 
strand probes (homozygous $A A$ and $C C$ ). Concentrations and optical density ratios were measured with the Nanodrop ND-1000 spectrophotometer (Thermo Fisher Scientific) as reported previously and dilutions were prepared to a final concentration of $80 \mathrm{ng} / \mu \mathrm{L}$.

The EMSA reactions were set up according to Ream et al. (2016) but using agarose instead of polyacrylamide gel. Trial tests were arranged to assess the performance of 2 binding buffers and to evaluate the best concentration of Sp1 transcription factor (Enzo Life Science Inc., Farmingdale, NY). Binding reactions were set up by incubating $0.5 \mathrm{BFU}$ (band-forming units) of $\mathrm{Sp} 1$ transcription factor in $1 \times$ Enzo buffer $(\mathbf{E B})$ with $40 \mathrm{ng}$ of DNA probe. The same Sp1 and DNA concentration were used with $1 \times$ binding buffer $(\mathbf{P B})$ suggested by Poletto et al. (2016). Enzo buffer consisted of $10 \mathrm{mM}$ HEPES, pH 7.9, $0.1 \mathrm{~m} M$ EDTA, 8.5\% glycerol, 170 $\mathrm{m} M \mathrm{KCl}, 1 \mu M \mathrm{ZnSO}_{4}, 37.5 \mu \mathrm{g} / \mathrm{mL}$ of Poly dIdC, 10 $\mathrm{m} M$ dithiothreitol, and $1 \mathrm{mg} / \mathrm{mL}$ of BSA. Poletto buffer consisted of $20 \mathrm{~m} M$ Tris- $\mathrm{HCl} \mathrm{pH} \mathrm{7.5,} 100 \mathrm{mM} \mathrm{KCl}$, $10 \mathrm{mM} \mathrm{ZnSO}$, $0.2 \%$ NP-40, $20 \%$ glycerol, and $5 \mathrm{mM}$ dithiothreitol, supplemented with $1 \mu \mathrm{g}$ of salmon sperm DNA. The use of 2 different formulations guaranteed that the diverse affinity observed was caused by the genotype only. After incubation at $37^{\circ} \mathrm{C}$ for $20 \mathrm{~min}$, the samples were loaded in $0.7 \%$ Tris-boric acid agarose gel and run at $30 \mathrm{~V}$ for $100 \mathrm{~min}$. Staining was performed in $1 \times$ SYBR Green (Thermo Fisher Scientific).

\section{Quantitative Real-Time PCR Analysis}

Comparative $S C D$ gene expression was examined in the 6 Mediterranean river buffaloes divided into 3 groups (2AA, $2 A C$, and $2 C C$ ) according to the genotype of SNP g.133A $>$ C. Quantitative real-time PCR was performed using 2-fold diluted cDNA products with PowerUp SYBR Green Master (Thermo Fisher Scientific). Analysis was carried out with a StepONE cycler (A pplied Biosystems, Foster City, CA) for 40 cycles at $95^{\circ} \mathrm{C}$ for $20 \mathrm{~s}$ and amplification at $60^{\circ} \mathrm{C}$ for 1 min. Amplification specificity was checked using melting curve following the manufacturer's instructions. Primers used for $S C D, \beta$-actin, and 18S rRNA expression are listed in Table 1. Each sample was analyzed in triplicate (technical replicates) and relative gene expression was determined using $\beta$-actin and $18 \mathrm{~S}$ as endogenous controls. Results are expressed as fold-change relative to the mean.

\section{Bioinformatic and Statistical Analysis}

The allele frequency and Hardy-Weinberg equilibrium ( $\chi^{2}$ test) were calculated for the sample of 303 buffaloes. Homology searches, comparison among se- quences, and multiple alignments were accomplished using DNAsis-Pro (Hitachi Software Engineering Co. Ltd., Yokohama, Japan). Binding of Sp1 was measured by band intensity values (mean \pm SEM) using Image $\mathrm{J}$ software (National Institute of Health; Bethesda, MD). Analysis of variance was used to examine Sp1 binding intensity and gene expression, followed by a StudentNewman-Keuls test using SPSS software (SPSS Inc., Chicago, IL). A $P$-value $<0.05$ was considered statistically significant.

Associations between $S C D$ genotype, fat percentage, single FA percentage, and FA classes (Supplemental Table S1; https://doi.org/10.3168/jds.2018-15059) were tested using the following mixed linear model:

$$
\begin{aligned}
y_{i j k l m n}= & \mu+A G E_{i}+D I M_{j}+\text { Month }_{k}+S C D_{l} \\
& +H E R D_{m}+C_{n}(S C D)+e_{i j k l m n},
\end{aligned}
$$

where $y_{i j k l m n}=$ dependent variable (Supplemental Table S1); $\mu=$ overall mean; $A G E_{i}=$ fixed effect of the $i$ th class of animals age at calving expressed in years $(6$ levels: $1=<4 \mathrm{yr}, 2=4 \mathrm{yr}, 3=5 \mathrm{yr}, 4=6 \mathrm{yr}, 7=5$ yr, $6=>7 \mathrm{yr}) ; D I M_{j}=$ fixed effect of the $j$ th stage of lactation (10 levels of $30 \mathrm{~d}$ each); Month $_{k}=$ fixed effect of the $k$ th month of calving (12 levels); $S C D_{l}=$ fixed effect of the lth $S C D$ genotype; HERD $D_{m}=$ random effect of the $m$ th herd; $C_{n}=$ random effect of individual buffalo cow nested within $S C D$ genotype; and $e_{i j k l m n}=$ random residual.

Pairwise comparisons among different levels of fixed effects included in model were performed using a Bonferroni adjusted test.

\section{RESULTS}

To assess the effect of the g.133A $>\mathrm{C}$ mutation on transcription of the $S C D$ gene, and to further validate the preliminary association with $\mathrm{FA}$, we genotyped a population of 303 Mediterranean river buffaloes by PCR-RFLP as shown in Table 2. The minor allele frequency (g.133C) was 0.25 and the population resulted in disequilibrium for Hardy-Weinberg $\left(\chi^{2}=7.96\right)$.

For the qualitative transcript analysis of the 6 samples with different genotypes (2AA, $2 A C$, and $2 C C$ ), 216 positive cDNA recombinant clones $(72$ clones for each genotype group) were screened by PCR and agarose gel electrophoresis. All of the analyzed cDNA clones were the same length. Ten clones per genotype were chosen for sequencing and no qualitative transcript variability was found among the cDNAs of the 3 investigated genotypes. In fact, the comparative sequence analysis indicated only completed assembled cDNAs from exon 1 to exon 6 for all clones. 
The binding of Sp1 transcription factor to DNA sequences including the SNP g.133A $>C$ was assessed using an EMSA. Specific probes corresponding to homozygous genotypes were tested with 2 binding buffers. The 2 genotypes revealed positive binding reactions in both experimental conditions; however, the complex genotype CC-Sp1 showed a stronger intensity than genotype $A A$ for both $\mathrm{EB}(201.77 \pm 4.06$ vs. $141.65 \pm$ $3.77 ; P<0.000)$ and $\mathrm{PB}(95.90 \pm 1.15$ vs. $67.30 \pm 2.14$; $P<0.000 ;$ Figure 1).

Furthermore, a real-time PCR experiment was performed to confirm the putative effect of the g.133A $>$ C genotype on the amount of transcribed mRNA. Two housekeeping genes were used ( $\beta$-actin and 18S rRNA) and gave the same normalization results. Relative $S C D$ expression from the same group of samples showed the highest values for the genotype $C C$, whereas the heterozygous $A C$ showed the lowest expression. The genotype $C C$ was significantly upregulated compared with both $A A$ and $A C$ genotypes $(P<0.01)$, and genotype $A A$ was upregulation compared with $A C(P<0.05)$ as shown in Figure 2 ( $\beta$-actin normalization).

The analysis of the relationship between the $S C D$ genotype and FA profile showed significant associations with different groups of FA (Table 3). In particular, heterozygous $(A C)$ buffalo cows had the highest value for MUFA $(P=0.010)$, oleic acid (C18:1 cis-9; $P=$ $0.005)$, PUFA $(P=0.030)$, and odd- and branchedchain fatty acids (OBCFA; $P=0.047$ ), as well as the lowest content for SFA $(P=0.007)$, and lowest atherogenic $(P=0.012)$ and thrombogenic $(P=0.003)$ indices compared with the $A A$ genotype (Table 3 ).

\section{DISCUSSION}

Genetic variability of $S C D$ in Italian Mediterranean buffaloes was investigated in our previous studies and SNP g.133A >C was identified and associated with milk yield (Pauciullo et al., 2012) and, preliminarily, with the total desaturation level of milk fat (Pauciullo et al., 2010). These associations were thought to be a consequence of a novel Sp1 binding site discovered in silico, which generates a cluster of $3 \mathrm{Sp} 1$ consensus sequences in the gene promoter. In the present work, we applied a comparative quali-quantitative approach to establish the role of this SNP on $S C D$ gene transcription. Furthermore, we carried out an association study with milk FA to elucidate the effect of the genotype on this trait in river buffaloes.

A preliminary genotyping on 303 milking buffaloes was necessary to identify their genotype at the locus g.133A >C and to select groups for the quali-quantitative analysis. Genotype distribution indicated that the variant $C$ was less frequent $(0.25)$ in the population. This value is slightly higher than frequencies estimated in our previous studies (0.16; Pauciullo et al., 2010, 2012). This might be due to several reasons including an indirect selection for other traits that favored the $C$ allele, nonrandom matings, or simply the greater number of farms involved in the present study.

After genotyping, 6 buffalo cows (2 per each genotype) were chosen for investigating the effect of the SNP g.133A $>$ C on the RNA through a comparative quali-quantitative analysis. The qualitative analysis of cDNA populations did not show any differences in the primary transcripts; only correctly assembled cDNAs (from exon 1 to 6) were found.

It is known that the first element affecting the intricate mechanism of the RNA maturation, which reflects the occurrence of splicing events, is the extremely split architecture of the genes (Heyn et al., 2015). In this respect, our result is not surprising. In fact, unlike other genes expressed in the mammary gland and well studied from a transcript point of view (Ramunno et al., 2005; Gu et al., 2017), $S C D$ consists of only 6 exons (Pauciullo et al., 2010). However, the lack of splicing events is in conflict with our previous findings. Pauciullo et al. (2007) reported at least 5 different cDNA populations, among which the most represented transcript $(\sim 52 \%)$ was correctly assembled, followed by minor transcripts. In particular, a very short cDNA (only 565 bp long) was observed, with a substantial part of the exons deleted due to alternative splicing. Such a difference with the present results might be attributable to the

Table 2. Genotypes, allele frequency, and relative frequencies for the SNP g.133A $>$ C in the stearoyl CoA desaturase gene $(S C D)$ in river buffalo ${ }^{1}$

\begin{tabular}{|c|c|c|c|c|c|c|c|c|c|}
\hline \multirow[b]{2}{*}{ Item } & \multicolumn{4}{|c|}{ Genotype distribution } & \multicolumn{2}{|c|}{ Allele frequency } & \multicolumn{3}{|c|}{ Relative frequencies used in the model } \\
\hline & $A A$ & $A C$ & $C C$ & Total & $A$ & $C$ & Genotype & $\%$ of cows & No. of farms \\
\hline \multirow[t]{3}{*}{ Expected } & 170.81 & 113.37 & 18.81 & & & & $A C$ & $31.3 \%$ & 14 \\
\hline & & & & & & & $C C$ & $9.3 \%$ & \\
\hline & & & & & & & Total & $100 \%$ & 14 \\
\hline
\end{tabular}

${ }^{1} \chi^{2}=7.96 ; \mathrm{df}=1$. 
a)
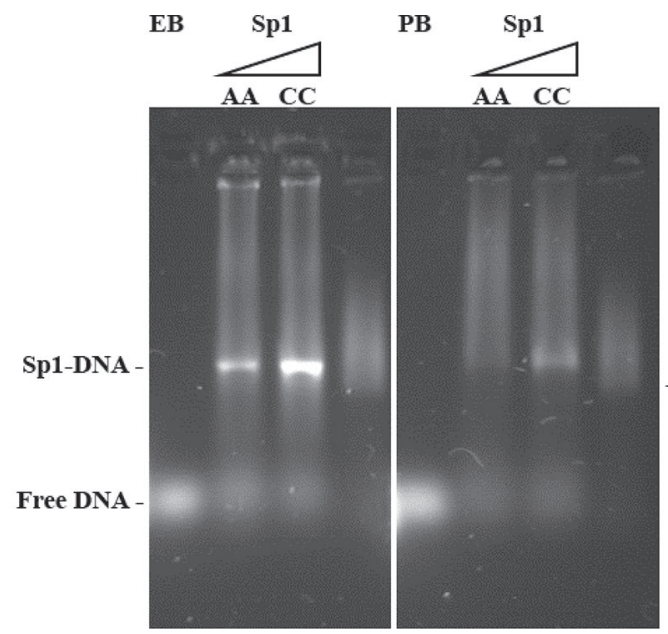

b)

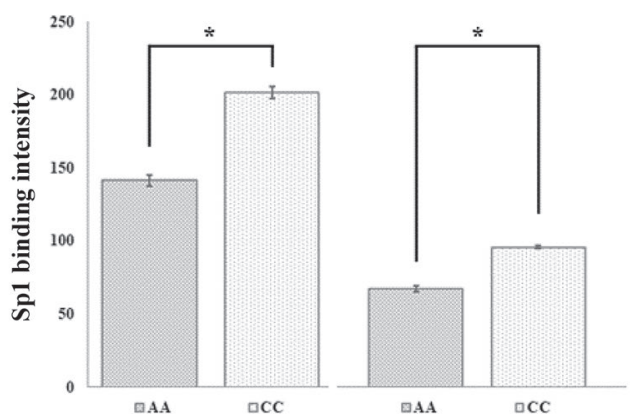

Figure 1. (a) Agarose electrophoresis mobility shift assay (EMSA) measuring the binding activity of the transcription factor Sp1 to the $S C D$ promoter constructs (homozygous $A A$ and $C C$ ) for 2 binding buffers, Enzo buffer (EB) and Poletto buffer (PB). (b) Densitometric quantification of the DNA-protein complex binding. For each gel, free DNA was added to lane 1, and Sp1 was added to lanes 2, 3, and 4. Sp1 binding intensity values are shown as mean \pm SEM for each genotype and each buffer. Band intensity was read 5 times by ImageJ (National Institutes of Health, Bethesda, MD) as result of independent experiments. Asterisks $(*)$ indicate significant differences $(P<0.000)$.

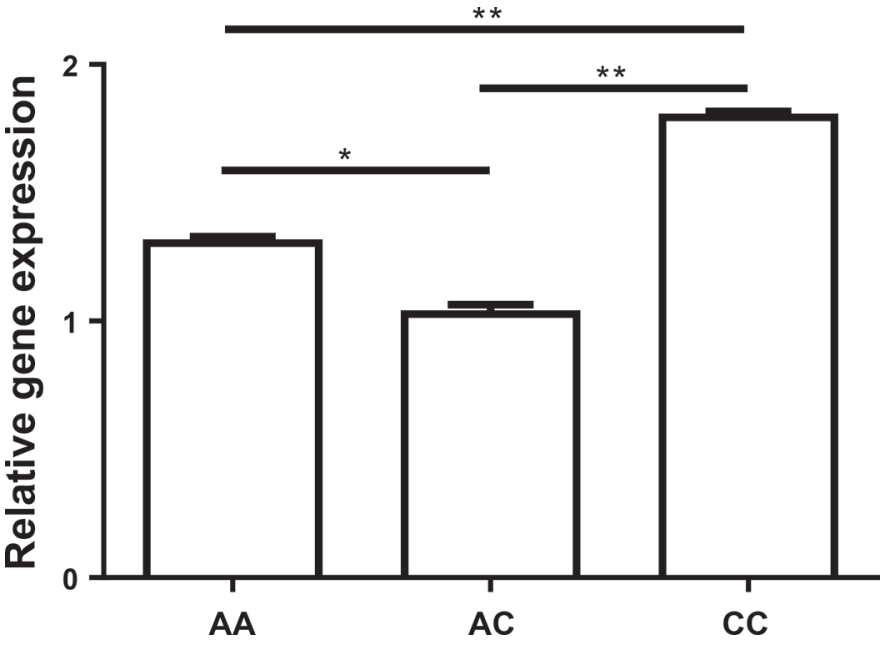

Figure 2. Relative expression values (mean \pm SD) of 2 subjects for each g.133A $>$ C genotype. Milk somatic cells were used for RNA isolation and real-time PCR. Unpaired Student's $t$-test, ${ }^{*} P<0.05$; $* * P<0.01$.

diverse sampling criteria achieved by the selection of milk samples with extreme fat content (Pauciullo et al., 2007).

The lack of qualitative differences among the $S C D$ transcripts led us to investigate the interaction of g.133A $>$ C with the Sp1 transcription factor and then to assess its effect on the quantity of transcripts.

An EMSA experiment was set up to address the first point; EMSA is a powerful method used to test the ability of proteins to selectively bind specific doublestranded DNA sequences. The technique compares the electrophoretic mobility of a free DNA sequence with the mobility of the same DNA sequence incubated with a protein or a mixture of proteins. Specific proteinDNA interaction results in reduced migration rate of

Table 3. Least squares means $( \pm \mathrm{SE})$ for the 3 genotypes of the SNP g.133A $>$ C for significant fat-related traits

\begin{tabular}{|c|c|c|c|c|}
\hline \multirow[b]{2}{*}{ Fat-related trait ${ }^{1}$} & \multirow[b]{2}{*}{$P$-value ${ }^{2}$} & \multicolumn{3}{|c|}{ Genotype $^{3}$} \\
\hline & & $A A$ & $A C$ & $C C$ \\
\hline SFA & 0.007 & $72.00^{\mathrm{A}} \pm 0.59$ & $70.69^{\mathrm{B}} \pm 0.74$ & $71.90^{\mathrm{AB}} \pm 0.82$ \\
\hline MUFA & 0.010 & $24.81^{\mathrm{A}} \pm 0.52$ & $25.97^{\mathrm{B}} \pm 0.56$ & $24.93^{\mathrm{AB}} \pm 0.74$ \\
\hline C18:1 cis-9 & 0.005 & $18.80^{\mathrm{A}} \pm 0.46$ & $19.92^{\mathrm{B}} \pm 0.49$ & $19.17^{\mathrm{AB}} \pm 0.65$ \\
\hline PUFA & 0.030 & $3.08^{\mathrm{a}} \pm 0.10$ & $3.23^{\mathrm{b}} \pm 0.10$ & $3.08^{\mathrm{ab}} \pm 0.13$ \\
\hline OBCFA & 0.047 & $3.87^{\mathrm{ab}} \pm 0.11$ & $3.95^{\mathrm{a}} \pm 0.11$ & $3.75^{\mathrm{b}} \pm 0.13$ \\
\hline Atherogenic index & 0.012 & $3.04^{\mathrm{A}} \pm 0.11$ & $2.82^{\mathrm{B}} \pm 0.11$ & $3.01^{\mathrm{AB}} \pm 0.15$ \\
\hline Thrombogenic index & 0.003 & $2.35^{\mathrm{A}} \pm 0.07$ & $2.20^{\mathrm{B}} \pm 0.08$ & $2.31^{\mathrm{AB}} \pm 0.09$ \\
\hline
\end{tabular}

$\overline{\mathrm{a}, \mathrm{b}}$ Means with different lowercase superscripts within a row differ $(P<0.05)$.

${ }^{\mathrm{A}, \mathrm{B}}$ Means with different uppercase superscripts within a row differ $(P<0.01)$.

${ }^{1} \mathrm{C} 18: 1$ cis-9 = oleic acid; OBCFA $=$ odd-branched chain fatty acids; atherogenic index $[\mathrm{C} 12: 0+(4 \times \mathrm{C} 14: 0)$ + C16:0]/[(PUFA $)+($ MUFA $)]$; thrombogenic index $($ C14:0 + C16:0)/[(0.5 $\times$ MUFA $)+(0.5 \times \mathrm{n}-6)+(3 \times$ $\mathrm{n}-3)+(\mathrm{n}-3: \mathrm{n}-6)]$.

${ }^{2}$ Significance level of the SNP effect.

${ }^{3}$ As reported in Table 2, $180 A A(59.4 \%), 95 A C(31.3 \%)$, and $28 C C(9.3 \%)$ were included in the analysis. 
this complex compared with the free DNA (Garner and Revzin, 1981). In this respect, 2 specific DNA constructs (homozygous $A A$ and $C C$ ) corresponding to the promoter region of $S C D$ were generated and each treated with a recombinant $\mathrm{Sp} 1$ transcription factor in 2 different binding buffers. The Sp1 interacted functionally with the promoter of both DNA constructs. This confirms, de facto, the bioinformatics results reported in previous studies, where at least $2 \mathrm{Sp} 1$ binding sites were presumed to characterize the region -473 to -448 of the SCD promoter (Pauciullo et al., 2010, 2012). In addition, the genotype $C C$ showed a higher binding affinity to Sp1 irrespective of the buffer used (Figure 1 ). The sequence analysis suggests the formation of a further consensus site falling between 2 existing Sp1 binding sites. However, the coexistence of 3 active sites in such a short DNA region seems functionally difficult for steric hindrance. Because DNA has one helical turn every $10.5 \mathrm{bp}$, the binding of another Sp1 transcription factor would completely straighten the molecule; furthermore, Sp1 transcription factors have a footprint that extends beyond their binding sites (Pascal and Tjian, 1991). Therefore, a higher band intensity of the genotype $C C$ and lack of a "super shift" in the EMSA assay suggests only a higher affinity of the allele $C$ for Sp1 binding sites (Figure 3).

The Sp1 motifs are well-known enhancer elements for the basal expression of many genes, including $S C D$, where they cover conserved promoter regions fundamental for gene expression (Keating et al., 2006; Pauciullo et al., 2012). Furthermore, these motifs often occur in clusters generated by variable number tandem repeats (VNTR; Fürbass et al., 2006; Wang et al., 2008). Their variability might regulate the transcription rate of the gene, as demonstrated for instance in other key genes involved in milk triacylglycerol synthesis or related to lipid droplet formation and secretion. For instance, the $D G A T 1$ VNTR polymorphism in cattle results in a different number of a binding motif for the transcription factor Sp1 with potential functional effects (Fürbass et al., 2006). In addition, alteration of Sp1 expression in goat mammary epithelial cells changes the expression of

\section{g.133 AA}
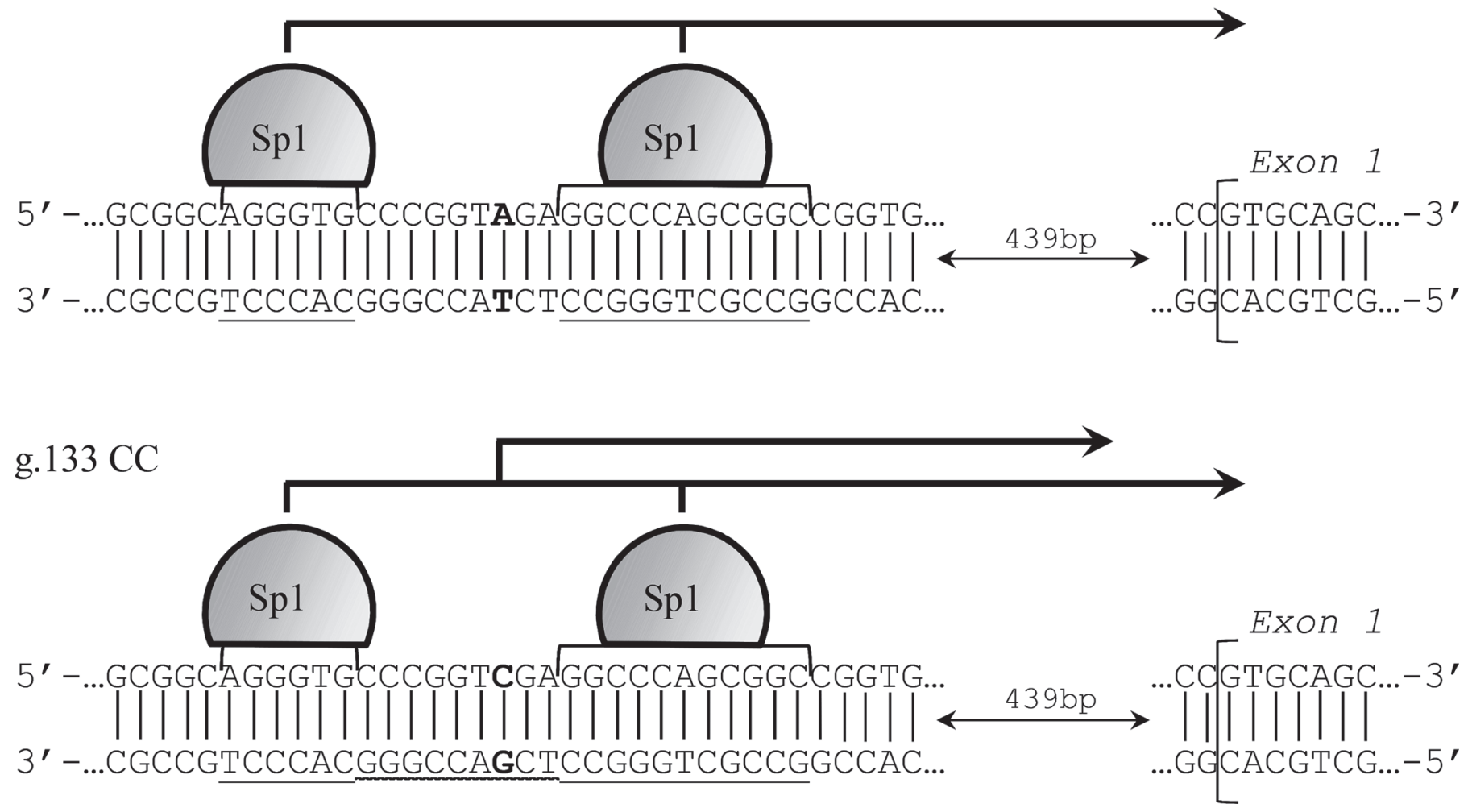

Figure 3. Schematic representation of the Sp1 motif cluster and binding. The sequence analysis of the homozygous $C C$ genotype showed an additional Sp1 motif generated by the SNP g.133 A>C in the promoter region of SCD (EMBL ID: FM876222). The SNP likely increases Sp1 binding affinity to the promoter region by adding an additional Sp1 binding site. This results in higher gene expression of the $C C$ genotype in the mammary gland. Sp1 binding sites are underlined, whereas the waved underlining indicates the additional Sp1. Nucleotide differences between the genotypes are in boldface. 
other lipogenic genes, such as DGAT1, DGAT2, TIP4\%, and $A D F P$ (Zhu et al., 2016) and affects the expression level of peroxisome proliferator-activated receptor- $\gamma$ $(P P A R G)$ and liver $\mathrm{X}$ receptor $\alpha(L X R A)$, both of which are crucial in regulating fatty acid metabolism together with sterol regulatory element-binding protein 1 (SRBP1; Zhu et al., 2015).

The highest affinity of Sp1 transcription factor for the $C$ allele also led us to investigate the effect of the $\mathrm{SNP}$ on the $S C D$ transcription level. The qPCR showed a significant upregulation of the genotype $C C$ compared with both the $A A$ and $A C$ genotypes $(P<0.01) ; A C$ showed the lowest expression.

In a previous study, the genotype $A C$ showed an over-dominance effect associated with milk yield, and buffaloes with this genotype showed higher milk yield compared with $A A$ and $C C$ (Pauciullo et al., 2012). It is well known that fat and milk yield are negatively correlated traits in buffalo (Kholif, 1997; Yadav et al., 2013), as in other dairy species, which might be consistent with the lowest AC expression.

The highest expression of genotype $C C$ is in agreement with the results of the EMSA experiments. In particular, the $C$ allele induced a higher Sp1 binding affinity, which consequently affected gene expression. In addition, the association study with different groups of FA indicated that the $A C$ and $C C$ genotypes showed the highest values for MUFA, mainly due to oleic acid (C18:1 cis-9), PUFA, and OBCFA. This profile was confirmed by a lower content of SFA, which consequently led to lower atherogenic and thrombogenic indices (Table 3). The latter indices are considered an important way of classifying milk FA because they measure the benefits of n-3 FA in the prevention of heart disease (Ulbricht and Southgate, 1991). Overall, our data agree with the atherogenic and thrombogenic indices recently reported by Santillo et al. (2016) on buffalo milk. Furthermore, to our knowledge, the current study represents one of the first indications of genetic association with these traits for the river buffalo.

The lack of correlation between $S C D$ mRNA expression and desaturase indices (i.e., apparent $S C D$ / $\Delta^{9}$-desaturase activity assessed by comparing product to precursor FA ratios) was unexpected. However, in this respect, the literature is often contradictory. For instance, in dairy cows, the pattern of $S C D$ mRNA was not significantly correlated with any of the $\Delta^{9}$ desaturase indices, and was nearly opposite to the overall $\Delta^{9}$-desaturase index when considering the lactation cycle (Bionaz and Loor, 2008). Conversely, a positive correlation of $S C D$ mRNA with oleic acid (Barber et al., 2000) and desaturase indices (Bernard et al., 2005) was observed in lactating sheep and goat, respectively. These conflicting data evidence more intricate de- saturation mechanisms at the level of the mammary gland, which even under the same feeding condition, likely depend on other factors, including mobilization of triacylglycerol from adipose tissue, selective uptake of stearic acid from blood very low density lipoprotein, plasma level of oleic acid, and so on (for a review, see Barber et al., 1997).

Therefore, in the present study, the allele $C$ revealed a better desaturation profile and, in a previous work, genotype $A C$ showed a greater milk yield (Pauciullo et al., 2012), showing a putative positive correlation under the control of the same genotype. In this respect, our data confirm the positive correlation of unsaturated C18 FA with milk yield found by Stoop et al. (2008) in dairy cows. Although the greater desaturase activity was hypothesized to correspond to fewer nutrients directed toward milk yield (Macciotta et al., 2008), our findings agree with previous reports, demonstrating that prolonged selection for increased milk yield did not alter the content of the majority of individual milk fatty acids (Kay et al., 2005).

The association of the allele $C$ with the OBCFA $(P=0.047)$ also deserves attention. Recently, other fundamental genes for milk traits have been positively associated with OBCFA in river buffalo. For instance, Cosenza et al. (2017) found higher contents of these FA associated with the SNP g.129C $>\mathrm{T}(P<0.0006)$ at the oxytocin receptor gene $(O X T R)$, whereas the marker g. $11188 \mathrm{~A}>\mathrm{G}$ at the prolactin receptor gene $(P R L R)$ tended to have a significant effect $(P<0.06)$ on the same traits (Cosenza et al., 2018). This class of FA in milk fat are mostly derived from rumen bacteria, although linear odd-chain FA might be synthesized de novo in the mammary gland (Vlaeminck et al., 2006). In ruminants, OBCFA are mainly used as biomarkers of rumen functionality (Craninx et al., 2008; Stefanov et al., 2010), whereas in human, OBCFA show anticarcinogenic effects (Wongtangtintharn et al., 2004) and are therefore considered an emerging class of bioactive FA, comparable to that of CLA (Bainbridge et al., 2016).

In this context, $S C D$ g. $133 \mathrm{~A}>\mathrm{C}$ is a good candidate for increasing the milk FA desaturation level and, together with SNP in other genes, may contribute to the improvement of river buffalo milk quality.

\section{CONCLUSIONS}

The quality of buffalo milk is essential to satisfy the requests of an increasing market demand of related dairy products. Therefore, genes involved in fat metabolism are important targets of study to achieve this goal. In the present study, we elucidated the role of $S C D$ g.133A $>$ C on gene transcription and investigated 
possible associations with milk fat traits. No alternative splicing events were found in the 3 investigated genotypes; therefore, the SNP had no influence on transcript quality. However, EMSA demonstrated that the $A$ to $C$ substitution generated a higher binding affinity of the Sp1 transcription factor to the gene promoter. The stronger Sp1 binding produced a quantitative difference in gene expression, albeit not directly linked to desaturation activity of $S C D$ in mammary gland. The allele $C$ was associated with a different FA profile from the $A$ allele. Therefore, the SNP g.133A $>$ C is a marker with a dual impact on milk yield and FA desaturation level, making it an interesting candidate for assisted selection programs of the species.

\section{ACKNOWLEDGMENTS}

This research was financially supported by the project ProBufaLat (PAUA_RILO_17_01), Department of Agricultural, Forest and Food Sciences, University of Torino, Grugliasco (Italy) and, partially, by the project GenoBu (PON01_00486), Italian Ministry of Research. We are very grateful to the buffalo breeders for providing the samples for this research.

\section{REFERENCES}

ANASB. 2017. Associazione Nazionale Allevatori Specie BufalinaStatistiche dati nazionali. Accessed May 5, 2018. http://www .anasb.it/home.htm.

Bainbridge, M. L., L. M. Cersosimo, A.-D. G. Wright, and J. Kraft. 2016. Content and composition of branched-chain fatty acids in bovine milk are affected by lactation stage and breed of dairy cow. PLoS One 11:e0150386.

Barber, M. C., R. A. Clegg, M. T. Travers, and R. G. Vernon. 1997. Lipid metabolism in the lactating mammary gland. Biochim. Biophys. Acta 1347:101-126.

Barber, M. C., R. Ward, S. Richards, A. Salter, P. Buttery, R. Vernon, and M. Travers. 2000. Ovine adipose tissue monounsaturated fat content is correlated to depot-specific expression of the stearoylCoA desaturase gene. J. Anim. Sci. 78:62-68.

Bernard, L., J. Rouel, C. Leroux, A. Ferlay, Y. Faulconnier, P. Legrand, and Y. Chilliard. 2005. Mammary lipid metabolism and milk fatty acid secretion in alpine goats fed vegetable lipids. J. Dairy Sci. 88:1478-1489.

Bhattacharya, A., J. Banu, M. Rahman, J. Causey, and G. Fernandes. 2006. Biological effects of conjugated linoleic acids in health and disease. J. Nutr. Biochem. 17:789-810.

Bionaz, M., and J. J. Loor. 2008. Gene networks driving bovine milk fat synthesis during the lactation cycle. BMC Genomics 9:366.

Cosenza, G., M. Iannaccone, B. Auzino, N. Macciotta, A. Kovitvadhi, I. Nicolae, and A. Pauciullo. 2018. Remarkable genetic diversity detected at river buffalo prolactin receptor $(P R L R)$ gene and association studies with milk fatty acid composition. Anim. Genet. 49:159-168.

Cosenza, G., N. P. Macciotta, A. Nudda, A. Coletta, L. Ramunno, and A. Pauciullo. 2017. A novel polymorphism in the oxytocin receptor encoding gene $(O X T R)$ affects milk fatty acid composition in Italian Mediterranean river buffalo. J. Dairy Res. 84:170-180.

Craninx, M., A. Steen, H. Van Laar, T. Van Nespen, J. Martin-Tereso, B. De Baets, and V. Fievez. 2008. Effect of lactation stage on the odd-and branched-chain milk fatty acids of dairy cattle under grazing and indoor conditions. J. Dairy Sci. 91:2662-2677.

FAO. 2016. Food and Agriculture Organization of the United Nations. Statistics of live animals. Accessed May 5, 2018. http://www.fao .org/faostat/en/\#data/QA.

Fürbass, R., A. Winter, R. Fries, and C. Kuhn. 2006. Alleles of the bovine DGAT1 variable number of tandem repeat associated with a milk fat QTL at chromosome 14 can stimulate gene expression. Physiol. Genomics 25:116-120.

Garner, M. M., and A. Revzin. 1981. A gel electrophoresis method for quantifying the binding of proteins to specific DNA regions: Application to components of the Escherichia coli lactose operon regulatory system. Nucleic Acids Res. 9:3047-3060.

Gu, M., G. Cosenza, I. Nicolae, A. Bota, Y. Guo, L. Di Stasio, and A. Pauciullo. 2017. Transcript analysis at DGAT1 reveals different mRNA profiles in river buffaloes with extreme phenotypes for milk fat. J. Dairy Sci. 100:8265-8276.

Heyn, P., A. T. Kalinka, P. Tomancak, and K. M. Neugebauer. 2015. Introns and gene expression: cellular constraints, transcriptional regulation, and evolutionary consequences. BioEssays 37:148-154.

ISMEA. 2016. Istituto di Servizi per il Mercato Agricolo Alimentare - Produzione e fatturato della Mozzarella di Bufala Campana. Accessed May 5, 2018. http://www.ismeamercati.it/flex/ FixedPages/IT/QualidoScheda.php/L/IT/ID/308/BL/aHR0cDov L3d3dy5pc21lYW1lcmNhdGkuaXQvZmxleC9GaXhlZFBhZ2V zL0lUL1F1YWxpZG9WZXRyaW5hLnBocD9wPTcmYz0mY2F0 PS0xJnQ9LTEmcmduPS0x.

Kay, J. K., W. Weber, C. Moore, D. Bauman, L. Hansen, H. ChesterJones, B. Crooker, and L. Baumgard. 2005. Effects of week of lactation and genetic selection for milk yield on milk fatty acid composition in Holstein cows. J. Dairy Sci. 88:3886-3893.

Keating, A. F., J. J. Kennelly, and F.-Q. Zhao. 2006. Characterization and regulation of the bovine stearoyl-CoA desaturase gene promoter. Biochem. Biophys. Res. Commun. 344:233-240.

Kholif, A. M. 1997. Effect of number and stage of lactation on the yield, composition and properties of buffalo's milk. Egypt. J Dairy Sci. $25: 25-39$

Lengi, A. J., and B. A. Corl. 2007. Identification and characterization of a novel bovine stearoyl-coa desaturase isoform with homology to human SCD5. Lipids 42:499-508.

Macciotta, N. P. P., M. Mele, G. Conte, A. Serra, M. Cassandro, R. Dal Zotto, A. C. Borlino, G. Pagnacco, and P. Secchiari. 2008. Association between a polymorphism at the stearoyl CoA desaturase locus and milk production traits in Italian Holsteins. J. Dairy Sci. 91:3184-3189.

Medrano, J. F., A. Johnson, E. J. De Peters, and A. Islas. 1999. Genetic modification of the composition of milk fat: Identification of polymorphisms within the bovine stearoyl-CoA-desaturase gene. J. Dairy Sci. 82(Suppl. 1):71.

Mele, M., G. Conte, B. Castiglioni, S. Chessa, N. P. P. Macciotta, A Serra, A. Buccioni, G. Pagnacco, and P. Secchiari. 2007. Stearoylcoenzyme A desaturase gene polymorphism and milk fatty acid composition in Italian Holsteins. J. Dairy Sci. 90:4458-4465.

Moioli, B., G. Contarini, A. Avalli, G. Catillo, L. Orru, G. De Matteis, G. Masoero, and F. Napolitano. 2007. Effect of stearoyl-coenzyme A desaturase polymorphism on fatty acid composition of milk. J. Dairy Sci. 90:3553-3558.

Pascal, E., and R. Tjian. 1991. Different activation domains of Sp1 govern formation of multimers and mediate transcriptional synergism. Genes Dev. 5:1646-1656.

Pauciullo, A., G. Cosenza, A. D'Avino, L. Colimoro, C. Iorio, D. Nicodemo, D. Di Berardino, and L. Ramunno. 2007. Preliminary analysis of stearoyl Co-A desaturase gene transcripts in River buffalo. Ital. J. Anim. Sci. 6(Suppl. 2):283-286.

Pauciullo, A., G. Cosenza, A. D'Avino, L. Colimoro, D. Nicodemo, A. Coletta, M. Feligini, C. Marchitelli, D. Di Berardino, and L. Ramunno. 2010. Sequence analysis and genetic variability of stearoyl CoA desaturase $(S C D)$ gene in the Italian Mediterranean river buffalo. Mol. Cell. Probes 24:407-410.

Pauciullo, A., G. Cosenza, R. Steri, A. Coletta, A. La Battaglia, D. Di Berardino, N. P. Macciotta, and L. Ramunno. 2012. A single 
nucleotide polymorphism in the promoter region of river buffalo stearoyl CoA desaturase gene $(S C D)$ is associated with milk yield. J. Dairy Res. 79:429-435.

Pauciullo, A., and G. Erhardt. 2015. Molecular characterization of the llamas (Lama glama) casein cluster genes transcripts (CSN1S1, CSN2, CSN1S2, CSN3) and regulatory regions. PLoS One 10:e0124963.

Poletto, M., A. J. Legrand, S. C. Fletcher, and G. L. Dianov. 2016. p53 coordinates base excision repair to prevent genomic instability. Nucleic Acids Res. 44:3165-3175.

Ramunno, L., G. Cosenza, A. Rando, A. Pauciullo, R. Illario, D. Gallo, D. Di Berardino, and P. Masina. 2005. Comparative analysis of gene sequence of goat CSN1S1 F and $\mathrm{N}$ alleles and characterization of CSN1S1 transcript variants in mammary gland. Gene 345:289-299.

Ream, J. A., L. K. Lewis, and K. A. Lewis. 2016. Rapid agarose gel electrophoretic mobility shift assay for quantitating protein: RNA interactions. Anal. Biochem. 511:36-41.

Sambrook, J., and D. W. Russell. 2001. Molecular Cloning: A Laboratory Manual. No. v. 1. Cold Spring Harbor Laboratory Press, Cold Spring Harbor, NY.

Santillo, A., M. Caroprese, R. Marino, A. Sevi, and M. Albenzio. 2016. Quality of buffalo as affected by dietary protein level and flaxseed supplementation. J. Dairy Sci. 99:7725-7732.

Schennink, A., J. M. Heck, H. Bovenhuis, M. H. Visker, H. J. van Valenberg, and J. A. Van Arendonk. 2008. Milk fatty acid unsaturation: genetic parameters and effects of stearoyl-CoA desaturase (SCD1) and acyl CoA:diacylglycerol acyltransferase 1 (DGAT1). J. Dairy Sci. 91:2135-2143.

Stefanov, I., V. Baeten, O. Abbas, E. Colman, B. Vlaeminck, B. De Baets, and V. Fievez. 2010. Analysis of milk odd-and branchedchain fatty acids using Fourier transform (FT)-Raman spectroscopy. J. Agric. Food Chem. 58:10804-10811.
Stoop, W. M., J. Van Arendonk, J. Heck, H. Van Valenberg, and H. Bovenhuis. 2008. Genetic parameters for major milk fatty acids and milk production traits of Dutch Holstein-Friesians. J. Dairy Sci. 91:385-394.

Thering, B. J., D. Graugnard, P. Piantoni, and J. Loor. 2009. Adipose tissue lipogenic gene networks due to lipid feeding and milk fat depression in lactating cows. J. Dairy Sci. 92:4290-4300.

Ulbricht, T. L. V., and D. A. T. Southgate. 1991. Coronary heart disease: Seven dietary factors. Lancet 338:985-992.

Vlaeminck, B., V. Fievez, A. Cabrita, A. Fonseca, and R. Dewhurst. 2006. Factors affecting odd-and branched-chain fatty acids in milk: A review. Anim. Feed Sci. Technol. 131:389-417.

Wang, S., M. Wang, S. Yin, G. Fu, C. Li, R. Chen, A. Li, J. Zhou, Z Zhang, and Q. Liu. 2008. A novel variable number of tandem repeats (VNTR) polymorphism containing Sp1 binding elements in the promoter of XRCC5 is a risk factor for human bladder cancer. Mutat. Res. 638:26-36.

Wongtangtintharn, S., H. Oku, H. Iwasaki, and T. Toda. 2004. Effect of branched-chain fatty acids on fatty acid biosynthesis of human breast cancer cells. J. Nutr. Sci. Vitaminol. (Tokyo) 50:137-143.

Yadav, S. P., P. Sikka, D. Kumar, S. Sarkar, A. K. Pandey, P. S. Yadav, and R. K. Sethi. 2013. Variation in milk constituents during different parity and seasons in Murrah buffaloes. Indian J. Anim. Sci. 83:747-751

Zhu, J., J. Luo, H. Xu, H. Wang, and J. Loor. 2016. Altered expression of specificity protein 1 impairs milk fat synthesis in goat mammary epithelial cells. J. Dairy Sci. 99:4893-4898.

Zhu, J., Y. Sun, J. Luo, M. Wu, J. Li, and Y. Cao. 2015. Specificity protein 1 regulates gene expression related to fatty acid metabolism in goat mammary epithelial cells. Int. J. Mol. Sci. 16:18061820 . 